\title{
Long-term mortality after percutaneous coronary intervention with drug-eluting stents compared with coronary artery bypass grafting for multivessel and left main disease: a meta-analysis
}

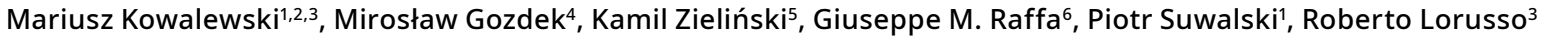 \\ 1 Department of Cardiac Surgery, Central Clinical Hospital of the Ministry of the Interior and Administration, Centre of Postgraduate Medical Education, Warsaw, Poland \\ 2 Thoracic Research Centre, Collegium Medicum, Nicolaus Copernicus University, Innovative Medical Forum, Bydgoszcz, Poland \\ 3 Cardiothoracic Surgery Department, Heart and Vascular Centre, Maastricht University Medical Centre, Maastricht, The Netherlands \\ 4 Department of Cardiology and Internal Medicine, Collegium Medicum, Nicolaus Copernicus University, Bydgoszcz, Poland \\ 5 Medical University of Warsaw, Warsaw, Poland \\ 6 Department for the Treatment and Study of Cardiothoracic Diseases and Cardiothoracic Transplantation, IRCCS_ISMETT (Istituto Mediterraneo per I Trapianti e Terapie ad alta \\ specializzazione), Palermo, Italy
}

Correspondence to: Mariusz Kowalewski, MD, PhD, Department of Cardiac Surgery, Central Clinical Hospital of the Ministry of the Interior and Administration, Centre of Postgraduate Medical Education, ul. Wołoska 137, 02-507 Warszawa, Poland, phone: +48225081200 , email: kowalewskimariusz@gazeta.pl Received: March 19, 2020. Revision accepted: May 27, 2020. Published online: May 28, 2020. Kardiol Pol. 2020; 78 (7-8): 759-761 doi:10.33963/KP.15397 Copyright by the Author(s), 2020
Introduction Several randomized controlled trials (RCTs) compared percutaneous coronary intervention (PCI) with coronary artery bypass grafting ( $C A B G)$ for the treatment of coronary artery disease (CAD). Coronary artery bypass grafting was associated with a long-term survival benefit as compared with PCI with bare metal stent implantation. Subsequent advances in interventional cardiology made such conclusions no longer valid. Percutaneous coronary intervention with drug-eluting stents (PCI-DES) showed lower rates of major adverse cardiovascular events. Tested against CABG, it resulted in similar safety outcomes but mainly at shortand mid-term follow-up. Whether this benefit persists at long-term follow-up ( $\geq 5$ years) remains inconclusive. Also, the available evidence is conflicting in various clinical scenarios of left main disease (LMD) versus multivessel disease (MVD). This short communication aimed to assess the mortality risk following PCI-DES compared with CABG in LMD and MVD, separately, based on the results of RCTs with long-term follow-up ( $\geq 5$ years).

Methods A meta-analysis was performed in accordance with the PRISMA (Preferred Reporting Items for Systematic Reviews and Meta-Analyses) statement. Online databases
(PubMed, MEDLINE, EMBASE, CENTRAL, and Web of Science) were screened until March 31, 2020. Randomized controlled trials or follow-up studies of RCTs comparing PCI-DES and CABG in LMD and / or MVD and reporting crude mortality data at follow-up equal to or longer than 5 years were considered eligible for further analysis. The study was approved by the local ethics committee. Patient informed consent to participate in the study was not required.

Statistical analysis Pooled odds ratios (ORs) and $95 \%$ CIs of mortality at reported follow-up equal to or longer than 5 years were calculated using a random effects model with the Mantel-Haenszel method. Heterogeneity was assessed with the Cochran Q test and publication bias by using a funnel plot with $\log \mathrm{OR}$ plotted against standard error.

Results and discussion Six studies ${ }^{1-6}$ enrolling 7312 patients and meeting inclusion criteria were included. Two studies ${ }^{2,5}$ were excluded, as they recruited patients with previous PCI. Detailed study characteristics are presented in Supplementary material, Table S1. Three studies $^{1,4,6}$ were focused on LMD. Two studies ${ }^{3,4}$ analyzed MVD only and defined MVD as significant stenosis in 2 or more major epicardial vessels 
จั Study or subgroup

Left main disease

Holm et al (2020), NOBLE

Park et al (2020), PRECOMBAT

Stone et al (2019), EXCEL

Thuijs et al (2019), SYNTAX Extended Survival

Subtotal $(95 \% \mathrm{CI})$

Total events

Heterogeneity: $\tau^{2}=0.01 ; \chi^{2}=4.02 ; d f=3(P=0.26) ; R^{2}=25 \%$

Test for overall effect: $Z=1.04(P=0.3)$

\section{Multivessel disease}

Farkouh et al (2019), FREEDOM Follow-On

Park et al (2015), BEST

Thuijs et al (2019), SYNTAX Extended Survival

Subtotal $(95 \% \mathrm{CI})$

Total events

Heterogeneity: $\tau^{2}=0 ; \chi^{2}=0.08 ; d f=2(P=0.96) ; P^{2}=0 \%$

Test for overall effect: $Z=3.57(P<0.001)$

Test for subgroup differences: $\chi^{2}=2.96 ; d f=1(P=0.09) ; P=66.2 \%$
PCI-DES CABG

Events Total Events Total Weight, \% M-H, Random, 95\% CI

$\begin{array}{rrrrrr}54 & 592 & 50 & 592 & 21.2 & 1.09(073-1.63) \\ 42 & 300 & 40 & 300 & 16.7 & 1.06(0.66-1.69) \\ 119 & 948 & 89 & 957 & 33.9 & 1.40(0.64-1.25) \\ & & & & & \\ 93 & 357 & 98 & 348 & 28.2 & 0.90(0.64-1.25) \\ & 2197 & & 2197 & 100 & 1.12(0.91-1.38)\end{array}$

308

277

$\begin{array}{rrrrrr}99 & 478 & 72 & 465 & 36 & 1.43(1.02-1.99) \\ 29 & 438 & 22 & 442 & 12.4 & 1.35(0.77-2.40) \\ 151 & 546 & 113 & 549 & 51.7 & 1.47(1.12-1.95) \\ & 1462 & & 1456 & 100 & 1.44(1.18-1.76)\end{array}$

OR

M-H, Random, 95\% CI

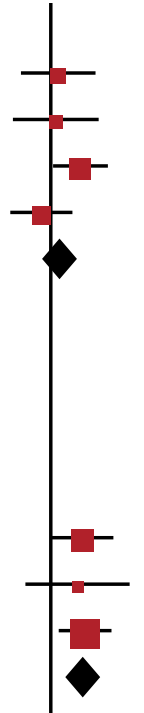

FIGURE 1 All-cause mortality for percutaneous coronary intervention (PCI) with drug-eluting stent (DES) implantation and coronary artery bypass grafting (CABG) Abbreviations: OR, odds ratio 
involving at least 2 separate coronary artery territories excluding LMD. The SYNTAXES (Synergy Between PCI with Taxus and Cardiac Surgery Extended Survival) study ${ }^{5}$ reported on both LMD and 3-vessel disease (significant stenosis in vessels supplying all 3 major epicardial territories excluding LMD), which contributed to the pooled analysis in MVD. Studies that contributed to the analysis of LMD included patients with LMD and a history of 2- or 3-vessel disease (Supplementary material, Table S1). No signs of publication bias were noted (Supplementary material, Figure S1). In total, 3659 subjects (50\%) underwent PCI-DES, and 3653 (50\%) underwent CABG. Patients were stratified to 2 subgroups: LMD (4.394 [60\%]) and MVD (2.918 [40\%]). In the LMD subgroup, the overall mortality was $585 / 4394$ (13.3\%) at a mean weighted follow-up of 6.83 years. There was no difference between PCI-DES and CABG with respect to all-cause mortality (OR, 1.12; 95\% CI, 0.91-1.38; $\left.P=0.3 ; I^{2}=25 \%\right)$ with the corresponding event rates of $14 \%(308 / 2197)$ and $12.6 \%(277 / 2197)$ for PCI-DES and CABG, respectively (FIGURE 1). In the MVD subgroup, the overall mortality was $486 / 2.918(16.7 \%)$ at a mean weighted follow-up of 8.01 years. Furthermore, PCI-DES was associated with a $44 \%$ increase of the mortality ORs as compared with CABG (OR, 1.44; 95\% CI, 1.18-1.76; $\left.P<0.001 ; I^{2}=0 \%\right)$ with the respective event rates of $19.1 \%(279 / 1462)$ and $14.2 \%$ (207/1.456) for PCI-DES and CABG. A difference between subgroup interaction $\left(P_{\text {int }}=0.09\right)$ did not reach statistical significance.

The current meta-analysis is the first to assess long-term ( $\geq 5$ years) mortality in patients undergoing PCI-DES compared with those undergoing CABG. Our subgroup analysis showed a relative $44 \%$ increase in mortality ORs for PCI-DES in the setting of MVD and equal safety in LMD. Together with a subgroup interaction of borderline significance, the meta-analysis demonstrated different risk profiles of patients with LMD or MVD, resulting from less or more diffuse CAD. Indeed, mortality in the PCI-DES arm was $14 \%$ versus $19.1 \%$ depending on the extent of CAD (LMD versus MVD). The mortality rates following CABG remained merely similar $(12.6 \%$ vs $14.2 \%)$. Completeness of revascularization, which is less frequently achieved with PCI-DES in MVD, must have also played some role. Another potentially relevant issue not addressed in neither RCT yet, is a medical history of PCI; a recent study showed less favorable outcomes in patients who underwent $\mathrm{PCI}$ prior to $\mathrm{CABG}$. $^{7}$ Lastly, coronary complexity should be also considered; in fact, current European Society of Cardiology/European Association for Cardio-Thoracic Surgery guidelines ${ }^{8}$ indicate that $\mathrm{PCI}$ is an appropriate alternative to CABG in LMD and low-to-intermediate anatomical complexity. On the other hand, among patients with LMD and high anatomical complexity, the number of patients studied in RCTs is low owing to exclusion criteria, so no recommendation can be made for $\mathrm{PCI}$ at the moment. Based on findings from previous studies, ${ }^{1,4}$ it becomes apparent that PCI-DES may be equally safe in the setting of LMD compared with CABG even in a long-term perspective. The above findings are also in line with a recent meta-analysis ${ }^{9}$ that found no significant differences between PCI and CABG regarding the all-cause mortality risk (relative risk, 1.03; 95\% CI, 0.81-1.32; $P=0.779$ ) or cardiac death (relative risk, 1.03; 95\% CI, 0.79-1.34; $P=0.817$ ) at a mean weighted follow-up of 5.5 years. Yet, in MVD, CABG confers a long-term survival benefit over PCI-DES because of higher rates of complete revascularization achieved and this has to be considered when tailoring treatment to patients' needs.

\section{SUPPLEMENTARY MATERIAL}

Supplementary material is available at www.mp.pl/kardiologiapolska.

\section{ARTICLE INFORMATION}

\section{CONFLICT OF INTEREST None declared.}

OPEN ACCESS This is an Open Access article distributed under the terms of the Creative Commons Attribution-NonCommercial-NoDerivatives 4.0 International License (CC BY-NC-ND 4.0), allowing third parties to download articles and share them with others, provided the original work is properly cited, not changed in any way, distributed under the same license, and used for noncommercial purposes only. For commercial use, please contact the journal office at kardiologiapolska@ptkardio.pl.

HOW TO CITE Kowalewski M, Gozdek M, Zieliński K, et al. Long-term mortality after percutaneous coronary intervention with drug-eluting stents compared with coronary artery bypass grafting for multivessel and left main disease: a meta-analysis. Kardiol Pol. 2020; 78: 759-761. doi:10.33963/KP.15397

\section{REFERENCES}

1 Park DW, Ahn JM, Park H, et al. Ten-year outcomes after drug-eluting stents versus coronary artery bypass grafting for left main coronary disease: Extended follow-up of the precombat trial. Circulation. 2020; 141: 1437-1446.

2 Farkouh ME, Domanski M, Dangas GD, et al. Long-term survival following multivessel revascularization in patients with diabetes: the freedom follow-on study. J Am Coll Cardiol. 2019; 73: 629-638.

3 Park SJ, Ahn JM, Kim YH, et al. Trial of everolimus-eluting stents or bypass surgery for coronary disease. N Engl J Med. 2015; 372: 1204-1212.

4 Holm NR, Makikallio T, Lindsay MM, et al. Percutaneous coronary angioplasty versus coronary artery bypass grafting in the treatment of unprotected left main stenosis: Updated 5-year outcomes from the randomised, non-inferiority noble trial. Lancet. 2020; 395: 191-199.

5 Thuijs D, Kappetein AP, Serruys PW, et al. Percutaneous coronary intervention versus coronary artery bypass grafting in patients with three-vessel or left main coronary artery disease: 10-year follow-up of the multicentre randomised controlled syntax trial. Lancet. 2019; 394: 1325-1334.

6 Stone GW, Kappetein AP, Sabik JF, et al. Five-year outcomes after PCI or CABG for left main coronary disease. N Engl J Med. 2019; 381: 1820-1830.

7 Bugajski P, Greberski K, Kuzemczak M, et al. Impact of previous percutaneous coronary interventions on the course and clinical outcomes of coronary artery bypass grafting. Kardiol Pol. 2018; 76: 953-959.

8 Neumann FJ, Sousa-Uva M, Ahlsson A, et al. Group ESCSD. 2018 ESC/EACTS guidelines on myocardial revascularization. Eur Heart J. 2019; 40: 87-165.

9 Ahmad Y, Howard JP, Arnold AD, et al. Mortality after drug-eluting stents vs. Coronary artery bypass grafting for left main coronary artery disease: A meta-analysis of randomized controlled trials. Eur Heart ]. 2020 Mar 2. [Epub ahead of print]. 